\title{
Public Perceptions Regarding Genomic Technologies Applied to Breeding Farm Animals: A Qualitative Study
}

\author{
Francis Z. Naab ${ }^{1}$, David Coles ${ }^{1,2}$, Ellen Goddard ${ }^{3}\left[\right.$ and Lynn J. Frewer ${ }^{1, *(1)}$ \\ 1 School of Natural and Environmental Sciences, Newcastle University, Newcastle upon Tyne NE1 7RU, UK; \\ francis.naab@bristol.ac.uk (F.Z.N.); david.coles@hazyrays.com (D.C.) \\ 2 Enhance International, The Bacchus, Elsdon, Newcastle upon Tyne NE19 1AA, UK \\ 3 Agricultural Marketing and Business, Faculty of Agricultural, Life and Environmental Sciences, \\ 515 General Services Building, University of Alberta, Edmonton, AB T6G 2H1, Canada; \\ egoddard@ualberta.ca \\ * Correspondence: lynn.frewer@newcastle.ac.uk; Tel.: +44-(0)7553152743
}

Citation: Naab, F.Z.; Coles, D.;

Goddard, E.; Frewer, L.J. Public Perceptions Regarding Genomic Technologies Applied to Breeding Farm Animals: A Qualitative Study. BioTech 2021, 10, 28. https://doi.org/ 10.3390/biotech10040028

Academic Editor: Maestri Enrico

Received: 8 April 2021

Accepted: 1 December 2021

Published: 3 December 2021

Publisher's Note: MDPI stays neutral with regard to jurisdictional claims in published maps and institutional affiliations.

Copyright: (C) 2021 by the authors. Licensee MDPI, Basel, Switzerland. This article is an open access article distributed under the terms and conditions of the Creative Commons Attribution (CC BY) license (https:// creativecommons.org/licenses/by/ $4.0 /)$.

\begin{abstract}
The societal acceptability of different applications of genomic technologies to animal production systems will determine whether their innovation trajectories will reach the commercialisation stage. Importantly, technological implementation and commercialisation trajectories, regulation, and policy development need to take account of public priorities and attitudes. More effective co-production practices will ensure the application of genomic technologies to animals aligns with public priorities and are acceptable to society. Consumer rejection of, and limited demand for, animal products developed using novel genomic technologies will determine whether they are integration into the food system. However, little is known about whether genomic technologies that accelerate breeding but do not introduce cross-species genetic changes are more acceptable to consumers than those that do. Five focus groups, held in the north east of England, were used to explore the perceptions of, and attitudes towards, the use of genomic technologies in breeding farm animals for the human food supply chain. Overall, study participants were more positive towards genomic technologies applied to promote animal welfare (e.g., improved disease resistance), environmental sustainability, and human health. Animal "disenhancement" was viewed negatively and increased food production alone was not perceived as a potential benefit. In comparison to gene editing, research participants were most negative about genetic modification and the application of gene drives, independent of the benefits delivered.
\end{abstract}

Keywords: breeding; ethics; farm animals; focus groups; genomics; public attitudes

\section{Introduction}

Much of the world population is still dependent on animals as a source of protein [1]. Increasing demand is a consequence of increased populations, incomes, and urbanisation in both low- and high-resource countries [2]. At the same time, there is increasing societal concern about ethical issues associated with animal welfare standards [3], such as, for example, intensive production systems [4] and the application of novel technologies to enhance animal production [5]. As a result, there has been a considerable focus within scientific and policy communities on the application of novel genomic technologies to improve animal production systems and disease resistance in livestock [6], including inter alia genetic modification [5], gene editing, such as CRISPR-Cas9 [7], and the prospective application of synthetic biology [8]. At the same time, there is a body of evidence to suggest that public acceptance of the application of genomic technologies to animal production systems is nuanced by the type of genomic technology being applied (e.g., genetic modification versus gene editing), the intended outcome of the modification (e.g., improved animal welfare or increased profitability), and the target organisms used in the modification (e.g., mammals, birds, or fish) [9]. Differences in public attitudes toward applying gene editing to 
agricultural crops have been observed when compared to genetic modification, and conventional breeding technologies are applied to meet the same objectives. Kato-Nitta et al. [10] report that participants in their survey tended to have more favourable attitudes toward gene editing than toward genetic modification when applied to crops. Attitudes toward the use of gene editing in plant breeding appear less firmly entrenched than for genetic modification [11,12]. It is notable that some applications of gene editing are more acceptable than others. Yunes et al. [13] report, in a quantitative study of gene editing applied to cattle, low public acceptance overall. In cases where support was given, it was highly dependent on the type and purpose of the application proposed. Similarly, Busch et al. [14] indicate that their participants evaluated the application of gene editing to promote disease resistance in humans most positively, followed by disease resistance in plants, and then in animals, but considered changes in product quality and quantity in cattle as the most negative outcome of gene editing.

The aim of the research presented here is to understand public perceptions of the use of different genomic technologies in breeding farm animals used in food production, including ethical concerns linked to different technological outcomes. An extensive body of literature regarding public perceptions and other socio-economic aspects of genetically modified animals or other genomic technologies such as cloning applied to food production and other areas of application is available (see, inter alia [15-17]), although less research has been conducted in relation to gene-edited animals. It has been established that the way people perceive new (food) technologies, for example, in relation to potential risks and benefits, determines whether they accept the development and implementation [18]. Risk perception refers to people's subjective judgments about the likelihood of negative occurrences, such as negative impacts on animal health or the environment, and is important in health and risk communication because it determines which hazards people care about and how they deal with them [19]. This includes communication about buying products produced using genomic technologies [20]. Risk perception is important to policy makers as the public may reject technologies that they perceive to be risky or unethical, independent of technical risk assessments provided by experts. It is important to note that research into risk perception reflects an objective analysis of public or consumer attitudes (Nuffield Council of Bioethics (2021) Genome editing and farmed animal breeding: social and ethical issues. NCOB, London, UK).

Advances in biotechnology have given rise to novel approaches to breeding farmed animals for human consumption. This includes, for example, breeding disease-resistant, healthier, and more productive animals (e.g., the case of CRISPR-Cas9 in pigs [21-23]), animal production systems with reduced environmental impacts, for example, in relation to greenhouse gas emissions [24], and producing animals more amenable to being managed in existing animal husbandry systems [25]. It is important to understand how citizens perceive the application of different genomic technologies in animal production systems, as they are unlikely to be adopted if there is societal opposition to their application, which is frequently underpinned by moral concerns [26]. Public acceptance may be linked to both the acceptability of the specific biotechnological process applied in the process of modification [9] and the developers' reason for applying it. For example, public concerns about the acceptability of animal products have focused on different issues, such as animal welfare [27,28] and environmental and human health concerns $[29,30]$.

The evolving legislative framework, the potential impact of public perceptions of risk, benefit, and ethical concern on this framework [31], and the extent to which consumer perceptions have contributed to the European Union's regulations regarding genetic modification within animal production systems clearly indicate [20] that consumer acceptability has to be taken into account.

However, differences in perceptions and attitudes need to be assessed in relation to different types of genomic application. Variations in legislative frameworks between diverse regions also exist. For example, within Europe, CRISPR-Cas9 technology is regulated in the same way as genetic modification (GM) [32], whereas in the US the resultant product 
is not considered GM. Hence, there exists a fundamental difference in approach where the US focus is on the ultimate "product", while the EU focus is on the "process" [33].

\section{Perceptions of, and Attitudes towards, Genomic Technologies Applied to Agriculture}

While there is an extensive body of literature on public perceptions of and attitudes towards the genetic modification of plants, and to some extent to animals and microorganisms, other areas of genomic science applied to food production, for example, using animals, have not been so extensively researched. However, there is some evidence that public attitudes to gene drives used in agriculture are, as for genetic modification, nuanced by moral concerns and associated attitudes [34]. Similar findings have been reported for agricultural applications of gene editing [35]. Generally, the focus of this body of research has tended to be on understanding public attitudes to biotechnological methods applied to plants. There is little research conducted in relation to some comparator technologies, for example, accelerated animal breeding, although there is some evidence that the public associate the latter with genetic modification [36].

The focus groups methodology was applied in order to (1) explore the attitudes of UK citizens towards some genomic technologies; (2) discuss and consider ethical dilemmas that may occur as a result of the use of genomic technologies in animal production systems.

\section{Materials and Methods}

Following ethical approval for the research (Newcastle University Ethics Committee, approval number 7235/2018), focus group discussions were used to initiate discourses between participants, allowing the researcher to decipher and moderate the divergent opinions [37]. Five (5) focus group discussions were organised, with 6-12 individuals in each group discussion. In total, 38 respondents participated, and the discussions took place between November and December 2018. Four focus group discussions were conducted in the city of Newcastle, and the fifth in a village in rural Northumberland. Each focus group discussion lasted between 50 and $70 \mathrm{~min}$ and was moderated by a trained researcher and an assistant. Saturation was reached during the fifth focus group discussion, with no further information being obtained.

\subsection{Recruiting Participants}

Initially, posters and flyers advertised for potential recruits on public notice boards. Respondents who expressed interest in taking part in the discussions were sent further information regarding the study's purpose and informed that if they were selected to take part, they would receive a GBP 10.00 shopping voucher. Interested respondents were sent a brief socio-demographic questionnaire to complete (age, occupation, gender, educational background, nationality, and dietary preferences). People below the age of 18 years were excluded, and participants with different socio-demographic characteristics were randomly allocated across the four urban and rural groups (Table 1). The results of the initial pilot group were included in the main analysis as no changes were made following the pilot.

Four of the discussions were held within Newcastle University and the fifth focus group discussion was held in Elsdon, a rural village $40 \mathrm{~km}$ north of Newcastle.

\subsection{Structure and Approach to Focus Group Discussions}

Participants were briefed on the discussions and asked to sign consent forms. They were subsequently randomly allocated numbers with which they were identified in the discussion in order to anonymise responses. They were from that point only referred to by their gender, random number, and the focus group in which they participated (e.g., a female that received the random number 3 , in focus group 1 , would be identified only as (F3, FG1). All focus groups followed the same protocols, developed by the authors of this paper. Each focus group discussion was preceded by a PowerPoint presentation where the moderator presented an overview of the technological issues discussed in the focus groups in relation to biotechnology. 
Table 1. Summary demographics of focus group discussion participants.

\begin{tabular}{|c|c|}
\hline VARIABLE & NUMBER (\%) \\
\hline \multicolumn{2}{|l|}{ Gender } \\
\hline Male (M) & $22(58)$ \\
\hline Female (F) & $16(42)$ \\
\hline \multicolumn{2}{|l|}{ Age groups } \\
\hline $18-30$ & $18(47.4)$ \\
\hline $31-43$ & $9(23.7)$ \\
\hline $44-56$ & $4(10.5)$ \\
\hline$>57$ & $7(18.4)$ \\
\hline Mean (age) & 37.6 \\
\hline \multicolumn{2}{|l|}{ Nationality } \\
\hline United Kingdom & $23(60.5)$ \\
\hline European & $3(8)$ \\
\hline Asian & $4(10.5)$ \\
\hline African & $7(18.4)$ \\
\hline Caribbean & $1(2.6)$ \\
\hline \multicolumn{2}{|l|}{ Employment status } \\
\hline Unemployed & $1(2.6)$ \\
\hline Paid employment & $15(39.5)$ \\
\hline Student & $18(47.4)$ \\
\hline Retired & $4(10.5)$ \\
\hline \multicolumn{2}{|c|}{ Self-stated dietary preferences } \\
\hline Asian & $1(2.6)$ \\
\hline None & $27(71)$ \\
\hline Halal & $3(8)$ \\
\hline Lacto-ovo free & $1(2.6)$ \\
\hline Vegan & $2(5.2)$ \\
\hline Vegetarian & $3(8)$ \\
\hline Non-Vegetarian Hindu & $1(2.6)$ \\
\hline
\end{tabular}

2.2.1. Part I-Attitude to Different Genomic Technologies Applied to Animal Production Systems

Participants were provided with descriptions of various genomic technologies applied to animals used in food production systems. As a "warm -up" exercise, participants were asked to rate how ethically acceptable they viewed each type of genomic technology listed on a scale of $0-5$, with 0 being unacceptable and 5 being entirely acceptable. The genomic technologies considered here were genetic modification (GM), structural genomics, functional genomics, conservation genomics, proteomics, and gene drive (see Table 2). Participants were asked to describe why they assigned the score given to that particular genomic technology, which then led to a group discussion of the various technologies about why the various technologies were or were not ethically acceptable. The aggregated results were provided as feedback to frame the discussion, but will not be considered further here because small sample sizes mean that statistical analysis is not appropriate. 
Table 2. Areas of genomic technology discussed.

\begin{tabular}{|c|c|c|}
\hline Type of Genomic Technology & Brief Description of Technology & $\begin{array}{l}\text { Examples of Application to Animal } \\
\text { Production Systems for Food Use }\end{array}$ \\
\hline Genetic Modification & $\begin{array}{l}\text { Changing the genetic makeup of cells, including the } \\
\text { transfer of genes within and across species boundaries, } \\
\text { to correct defects or produce improved and/or novel } \\
\text { organisms. }\end{array}$ & $\begin{array}{l}\text { Insertion into pigs of spinach gene to change } \\
\text { body composition for better food production. } \\
\text { Insertion of a modified gene to create animals } \\
\text { resistant to heat stress. }\end{array}$ \\
\hline Structural Genomics & $\begin{array}{l}\text { DNA sequencing, sequence assembly, sequence } \\
\text { organisation, and management and determination of } \\
\text { the structure of every protein encoded by the genome. }\end{array}$ & $\begin{array}{l}\text { Identifying animals with "desirable" genes, } \\
\text { e.g., greater productive yield, better disease } \\
\text { resistance. }\end{array}$ \\
\hline Functional Genomics & $\begin{array}{l}\text { Reconstruction of genome sequences to discover the } \\
\text { functions of the genes together. }\end{array}$ & $\begin{array}{l}\text { Identifying how genes interact to produce } \\
\text { desirable traits, e.g., animal behaviour, health, } \\
\text { and increase in productivity. }\end{array}$ \\
\hline Conservation genomics & $\begin{array}{l}\text { Use of genomic sequencing to better evaluate genetic } \\
\text { factors key to species conservation. }\end{array}$ & $\begin{array}{l}\text { Establishment of the size and health of a gene } \\
\text { pool or genetic diversity of a population } \\
\text { including preserving at-risk genotypes. }\end{array}$ \\
\hline Proteomics & $\begin{array}{l}\text { The large-scale study of the structure of proteins and } \\
\text { what their function is and how they interact in animals. }\end{array}$ & $\begin{array}{l}\text { Understanding of the function and regulation } \\
\text { of genes, and how these participate in complex } \\
\text { networks producing proteins and other } \\
\text { biological agents controlling the phenotypic } \\
\text { characteristics of a trait. }\end{array}$ \\
\hline Gene Drive & $\begin{array}{c}\text { Natural or genetically engineering the characteristics of } \\
\text { a particular trait so that it dominates other traits and } \\
\text { can propagate throughout a whole population or } \\
\text { species. }\end{array}$ & $\begin{array}{l}\text { Gene drives can be used to counter } \\
\text { animal-borne diseases and can either arise } \\
\text { naturally or be genetically engineered, e.g., } \\
\text { using CRISPR (gene editing) technology. }\end{array}$ \\
\hline
\end{tabular}

\subsubsection{Part II—Relative Importance of Genomic Technologies Applied to Animal} Production Systems

This section was designed to understand what participants thought about the different genomic technologies under consideration in relation to their potential impacts within society. Information was provided to participants linking some claimed potential benefits of the use of genomic technologies to breeding farm animals, including pigs and cattle.

\subsubsection{Part III—Ethical Dilemmas in the Use of Genomic Technologies}

Given that ethical concerns are raised as an important societal barrier to the adoption of GM in animal production systems, this was further explored in relation to each of the gene technologies under consideration. An important ethical question in animal breeding is the consideration of whether the "naturalness" (or "telos" (The telos of an animal is defined as "its nature or 'beingness'". Harfeld, J.L., 2013. Telos and the ethics of animal farming. Journal of agricultural and environmental ethics, 26(3), pp.691-709. In the focus groups, this was considered by participants as being linked to "naturalness" and so the two concepts are addressed together in the subsequent analysis and discussion.)) of animals should be preserved. The concept of naturalness was introduced to the groups, which led to their discussing the extent to which the animals themselves might ethically be adapted to their environment in order to promote and improve their welfare and facilitate their management. Both natural and unnatural methods of adaptation were discussed, including cases where some methods may lead to the "disenhancement" (Making an animal less sensitive to and more able to cope with adverse characteristics that may exist in its environment that may prove difficult to that animal species in its natural state, e.g., see Murphy, K.N. and Kabasenche, W.P., 2018. Animal disenhancement in moral context. NanoEthics, 12(3), pp. 225-236) of farm animals, and thus potentially affect their "telos". This may reflect a more biocentric perspective, which is, in a political, ecological, and literal sense, an ethical point of view that extends inherent value to all living things (see, inter alia [38,39]).

In order to facilitate and catalyse the discussions, two scenarios were presented to participants. These are provided in Appendix A.

Each scenario was discussed with participants in relation to the acceptability of each of the solutions with regard to animal welfare and the telos of the animals and whether 
applying the different genomic technologies to achieve the same goals would be preferable. Finally, the moderator encouraged the discussions to consider more general attitudes and perceptions of participants towards using genomic technologies in breeding farm animals, focusing on the various ethical considerations.

\subsection{Data Recording, Coding, and Analysis}

All discussions were recorded and transcribed. Preliminary codes were developed from notes taken during discussions and debriefing sessions. Thematic analysis was subsequently conducted on the transcripts using NVivo, version 20, QSR International, Melbourne, Brevard County, Australia. Thematic analysis is a qualitative data analysis method that involves reading through a dataset (such as transcripts from focus groups) and identifying patterns in meaning across the data [40]. Coding was initially validated using the first focus group transcript and further discussed by researchers. During this process, further codes (and subcodes) emerged. Codes and sub-codes were then organised into themes and sub-themes (Table 3). The remaining transcripts were then coded, and the coding scheme amended if additional themes emerged during the analysis. To maintain the anonymity of participants, the audio records were destroyed once transcription was completed and validated, in line with ethical requirements for participant anonymisation required by General Data Protection Regulation (GDPR) requirements. This may have limited subsequent reanalysis of participants' affective responses, but was appropriate given data protection regulation applied at the time of data collection.

Table 3. Codes and emerging themes from data.

\begin{tabular}{|c|c|}
\hline SUPERORDINATE THEME & CODE AND SUBCODE \\
\hline $\begin{array}{l}\text { Attitudes towards the use of different } \\
\text { genomic technologies }\end{array}$ & $\begin{array}{c}\text { Perception of the use of genomic technology } \\
\text { Genetic modification } \\
\text { Gene drive } \\
\text { Functional genomics } \\
\text { Structural genomics } \\
\text { Conservation genomics } \\
\text { Proteomics } \\
\text { Animal health and diseases } \\
\text { Animal welfare } \\
\text { General concerns about the use of genomic technologies }\end{array}$ \\
\hline $\begin{array}{l}\text { Prioritising the use of genomic } \\
\text { technologies }\end{array}$ & $\begin{array}{c}\text { The relative importance of genomic technologies } \\
\text { Animal health } \\
\text { Environmental sustainability } \\
\text { Animal welfare } \\
\text { Greater productivity } \\
\text { Safer human food } \\
\text { Efficient feed use } \\
\text { Telos }\end{array}$ \\
\hline $\begin{array}{l}\text { Ethical dilemmas from the use of } \\
\text { genomic technologies }\end{array}$ & $\begin{array}{l}\text { Animal welfare } \\
\text { Animal health } \\
\text { Free-range } \\
\text { Concerns } \\
\text { Religious concerns } \\
\text { Naturalness } \\
\text { Telos }\end{array}$ \\
\hline Additional concerns & $\begin{array}{l}\text { Climate change } \\
\text { Organic vs. inorganic production } \\
\text { Need for risk communication }\end{array}$ \\
\hline
\end{tabular}


The researchers discussed the various themes that emerged from the analysis. The quotes used in the text represent the emerging themes and the divergent opinions held by participants.

\section{Results}

All focus group discussions were highly interactive, with all participants engaging in the discussion. This reflects the level of interest, understanding, and knowledge of the participants relating to the subject area. In general, participants were open-minded and frequently challenged the views of other participants. Most of the participants agreed that there was a need to conduct genomic research into animal production. However, participants expressed divergent views concerning how the information should be applied. Some participants expressed specific cultural and ethical views about the use of various genomic technologies in animal breeding. In contrast, others were more positive about using genomic technologies if those technologies were appropriately regulated, and if societal preferences and priorities for technological innovation were taken into account. Some participants argued that genomic technologies could improve animal welfare and/or improve environmental sustainability. The overall conclusions of the discussions were broadly consistent across the five groups and reflected in the various themes presented in this research.

\subsection{Attitudes towards to the Use of Genomic Technology in Animal Production Systems}

The first part of the discussions involved participants assigning scores to six genomic technologies and then discussing their results with the rest of the group. The means of the scores were then calculated and used to complement the discussions that followed. Participants tended to agree about the acceptability of proteomics, conservation genomics, structural genomics, and functional genomics (see Table 2).

Participants were less positive about applying genetic modification and gene drives in breeding new traits in farm animals for human food production. Proteomics was rarely mentioned in the discussions, and participants were more confident in discussing conservation genomics and structural genomics. Participants associated structural genomics with traditional selective breeding.

... It's like selective breeding except you have more revision and knowledge to see what are actually selectively breeding towards ... if you are looking at the actual genes you know what you are aiming for, you don't have those mistaken ones, you have the good ones ... (M, FG2).

However, a few participants, after clarifying the meaning of both structural and functional genomics, were negative towards these applications and/or the use of information from them.

We've always done it for years, but we've just modernised it to an advanced state that now threatens our very existence (M, FG1).

Some participants indicated that natural selection is a natural process, but that this was not the case for all applications of genomic technologies. This line of reasoning represented a common thread through subsequent discussions. Participants held that understanding genomic structures and using that information for selective breeding of farm animals would benefit farmers. However, a majority of the participants expressed the view that such breeding processes should be "natural", for instance, by identifying, through genomic analysis, and then selecting pigs with a desirable trait to produce pigs with traits "useful" for supply chain requirements. Most participants expressed more negative opinions about genomic technologies perceived as "artificial” (especially GM and gene drives), especially for the development of animals with characteristics that could have unintended negative effects, with potentially severe consequences for human health and wellbeing as well as for the animal species concerned. 
I just think it could be dangerous, like getting rid of a gene or modifying it. Like what they did to mosquitoes, that's good, but if you start doing to the animals we eat, it's hard to model interactions as in the rest of the ecosystem, so it might result in something negative (F, FG2).

\subsection{Imposing a Global Control System}

Some participants expressed the view that there are potential benefits from the application of all the genomic technologies discussed if the route to application was cautious, precautionary, and appropriately regulated. However, they also recognised the difficulty of establishing an appropriate and consistent regulatory framework.

At first I indicated we should use these technologies with moderation, but how can we moderate their use, on a global scale, it has become increasingly difficult (F, FG 3).

So where do you draw the line when you start doing that? (F1, FG4).

Some participants did not believe that individual and country-level controls were adequate to moderate potentially extreme or maleficent use of genomic technologies:

...... there should be a global thing, ... ... there should be a global kind of system of policing, and you know the sort of ethical side (F1 and M2, FG5).

Participants expressed the need for industry and national regulation to introduce a system of governance that includes regulations based on ethical considerations as well as risk issues.

....... that code of conduct, that code of ethics, so there should be some mechanism by which they [industry and national governments] have to be held to accountable to (F1, FG5).

This was linked to the need to apply universal governance:

I think the most important part is to give the universal limits, I think that's the reason why the government exists, to set limits for some of these things (F3, FG4).

\subsection{Applications for Health Versus Food}

Participants agreed that there was a need to conduct research in these areas using animal genomic technologies. Many participants indicated that they thought there was the need to use genomics for fundamental research, particularly functional genomics, structural genomics, conservation genomics, and proteomics, in order to understand the nature of organisms.

I feel like there's a line between the research and the product ... I find important to do research because I feel that is the only way we would be able to understand anything after (M, FG 1).

The development and application of genomic technologies and their potential benefits were also regarded as important by some participants. While participants held generally negative views in relation to applying the genomic techniques to animals for food production purposes, participants were more positive about the application of genomic technologies for medical and veterinary research and to health care.

If we're all scared of manipulation, I'm not sure we would have gotten treatment for some of the diseases we have" (F3, FG3).

... we already know about the CRISPR/Cas9 technology and it's currently used in cancer technology and the treatment of cancer (F4, FG4).

... I think its uses in disease control, for example if this became an alternative to badger culling ...... (M, FG2).

Some study participants expressed reservations about the use of genomics and genomic technologies in this context, particularly if they involved the insertion of human genes in animals for the purposes of xenotransplantation. This view was sometimes expressed through the lens of religion. 
I think that these [genomic] technologies in general] would be more suited for sustaining food production ... but I don't agree too much with applying to human health, I feel like the human health, I think it's worse, and for me my religion doesn't permit that" (M, FG 1).

3.3.1. Fear of the Unknown, Novel or Unanticipated Outcomes in Animal Production Systems

The fear of the "unknown", which underpinned some participant concerns about using genomic technologies applied to animals for food production, was mainly linked to discussions on genetic modification and gene drives. This may be related to concerns about cross-species genomic technologies or perceptions of uncontrollability.

Mixing species is just mind blowing, it frightens me just the thought of mixing genes from different species (F1, FG5).

... it can propagate through the population-what if you were wrong, then you screwed it up basically (F1, FG3).

Many participants expressed a preference for the application of genomic technologies to conserve animal species compared to other potential benefits that could be generated from the use of such technologies. This was not particularly related to farm animals but related more generally to both domestic animals and those living in the wild. This is also consistent with views from discussions which suggest that participants were more open to the study and analysis of the genomes of animals and plants, which, in most cases, can be achieved through conservation genomics, proteomics, structural genomics, and functional genomics, but were highly sceptical about genetic modification and gene drives. However, many participants displayed some concerns about how knowledge gathered from the study of animal genomes might be applied in the future.

3.3.2. Perceptions of Benefits Associated with the Use of Genomic Technologies Applied to Animal Production Systems

For most participants, the beneficial aspects of genomic technologies linked to outcomes that would improve the lives of animals were considered to be the most important, for example, in relation to conservation genetics. These included:

\subsubsection{Animal Health and Welfare}

Discussion about animal health and welfare was an important topic for most participants and was closely linked to the concept that animal welfare equates to animal health and disease control.

... animal health ... control of animal welfare (F1, FG3).

... improved animal health which I think it probably crosses over to animal welfare, that idea of any common diseases, approach as many as you can sort of help identify you breed out diseases (M3, FG5).

While some participants perceived animal health as being distinct from animal welfare, the majority viewed animal health as part of animal welfare. Thus, genomic technologies were viewed to be helpful and important if they could be used to improve animal health and welfare. The majority of participants viewed animal welfare as an important consideration when using genomic technologies. Following the presentation of the case studies, some participants disliked the idea of using genomic technology to cause changes in animals. One participant described it as an "obvious violation" (F, FG1) of the rights of these animals and, to another, "absolutely unacceptable," (M2, FG2) or "inhumane".

However, a few participants disagreed, reasoning that:

... all animals were created in the perfect form, heat, drought, water resistant etc. ... you can find each animal is created in its form and place" (M5, FG2).

For some participants, genomic technologies were seen as advantageous to animal welfare and hence production. 
I don't think breeding to make them gentler and less aggressive is slightly less unethical [laughter] (M, FG4).

Some participants indicated that they felt that animal welfare was only used as a justification for genomic research insofar as this was a scientific bridge to improving human health.

... lot of the things we are talking about we're saying it's better for animals, they are not necessarily better for animals, they are better for us to get something out of the animals and I'm not sure if I am totally comfortable with that (F1, FG3).

Other participants indicated that, independent of the reasons why farmers might use genomic technologies (for example, to lower costs of production, increase productivity, and to improve environmental sustainably to mitigate the impacts of not using optimum animal husbandry practices), the welfare of animals should always be considered and given a high priority. Participants who held this view suggested that seeking the best welfare conditions for animals ultimately will lead to all other benefits that farmers may seek.

When the animal is feeling better, when the animal is feeling natural, when their wellbeing is enhanced then they will be more productive in the end, if they lived in a natural environment the food would be safer, they would feel more motivated and healthy (F1, FG4).

But basically you have got to link your low cost with your animal welfare, the two have got to come together (M5, FG5).

Some participants expressed the view that animal welfare problems were a consequence of human actions and that the conditions associated with animal husbandry should be changed to accommodate animal welfare needs, rather than developing new technological approaches to addressing animal welfare within these systems.

"If people want to continue eating meat, then surely they should change the environment that these animals are supposed to live in and not genetically modifying the animals to endure the conditions" (F2, FG2).

\subsubsection{Safer Human Food and Health}

Some participants emphasised the importance of the application of genomic technologies to improve human food security. In this context, some participants expressed concern about which genomic technologies should be applied to food production and the need to prioritise improved food safety over other beneficial impacts.

... Safer human food should be first [most important] because if you want for example a lot of the health problems we encounter nowadays can be traced to the food we eat... having a safe diet can help cut the risk of certain diseases like cancer (F3, FG4).

\subsubsection{Environmental Sustainability}

Participants indicated that environmental and ecological problems and factors linked to climate change could justify the application of many genomic technologies if their application mitigated these. For some participants, environmental sustainability was viewed as the most important potential impact of genomic technologies, leading to greater productivity, safer human food, improved animal health and welfare, and the preservation of ecosystems. However, one participant considered that the motives driving investment in genomic technologies were driven only by the financial interests of corporations and individuals.

The main thing and my fear is the money culture, you have separate ambitions and rules, and it can be an issue. I think it's disgusting to try to genetically modify the horrible life of an animal just for money, and it's nothing to do with global warming (F2, FG2).

\subsubsection{Low Cost and Greater Productivity}

The use of genomic technologies to improve productivity was viewed as a "game changer". Lower production costs and increased productivity associated with genomic 
technologies were viewed as important by some discussants, particularly in relation to global population growth.

I think with technology, we can produce more at very low cost to feed the increasing human population (M1, FG5).

Not all participants, however, held this view. Some associated the use of genomic technology with financial incentivisation on the part of industry stakeholders. The view was expressed that there is enough food to feed the world population, but food insecurity is driven by inequitable food distribution of food and food waste in supply chains.

... For me, I don't think there is scarce food in the world, there is abundance of food, it is a problem of the distribution of the food that is causing all the food insecurity in the world" (M, FG1).

"The whole thing that screams at me ... it says it's all to do with lower cost and greater productivity ... meanwhile the only reasons is to financially drive us to where and what we don't need (M1, FG5).

\subsubsection{Naturalness and Temperament}

Participants were generally not in favour of applying any genomic breeding techniques that resulted in the modification of the temperament or telos of animals. There was some difference of opinion amongst participants as to whether animal "naturalness" or animal temperament were more important in this regard.

Naturalness, that's highly important ... the animals should be living their natural lives in a as close to it as possible... (M, FG1).

Temperament is slightly more important than naturalness, because by the time you have been domesticating animals for ten thousand years a lot of the naturalness [is lost] (M2, FG2).

\section{Ethical Concerns}

The specific ethical scenarios considered during the discussions focused to a considerable extent on participant opinion on the use of genetic modification. The common themes that were consistent across the focus groups included animal rights and welfare, telos, access to more extensive conditions in which animals could be reared, and due consideration of alternatives to the use of genomic technologies.

\subsection{Telos (Naturalness)}

Many participants discussed the importance of maintaining the "naturalness" or telos of farm animals. The use of genomic technologies that completely change the natural characteristics, or attributes perceived to be natural, of farm animals was unacceptable. The view was expressed that the phenotypical features of animals were integral to the nature of the animal and existed for a reason.

... While chickens use their eyes to see and beaks to feed, pigs wag their curly tails as a result of emotional expression (M, FG1).

it's disgusting to .... remove beaks, eyes or tails of animals or do anything that will make them look less animals (F2, FG2)

Any changes in the phenotype of animals, unless it was for welfare and animal health which ultimately led to better productivity, were viewed to be unethical. Breeding to change the temperament of animals was seen by the majority as a violation of their fundamental nature and "natural rights", and thus was not considered welfare-driven.

In terms of naturalness, the aggression might be useful to the pig, it might be their nature to be aggressive (M, FG1).

Participants who expressed concerns about genomic technologies in animal welfare also indicated that these concerns also had an ethical basis. Alternative futures that did not involve genomic technologies were described. 


\section{Reduced Meat Consumption}

Some participants emphasised the need to reduce meat consumption. Other participants expressed the view that they were in favour of reduced meat production while giving livestock appropriate space to enjoy their natural habitats. These discussants claimed that increased societal demand for meat is driven by increasing meat supply, which makes the meat very cheap. This, in turn, triggers the need for the introduction of genomic technological innovations.

I think people are going to have to get used to the fact they have to pay more for their meat, it's too cheap ...

... In an ideal world we would all eat less meat, and we would have much higher welfare chickens (F1, FG3).

\subsection{Overall Concerns about the Use of Genomic Technologies in Animal Production Systems}

\subsubsection{Use of Genomic Information and Technology}

While there was a general agreement that the study of the structure and functions of the animal genomes was important, some participants had concerns about the ways in which the resulting information might be used, and that genetic information should only be used to promote animal health and welfare.

... I have no problem with that, it's just doing DNA analysis and obtaining information, it's what you do with that information that is potentially disturbing (F, FG 3).

Any technology that doesn't seek to improve animal health, helping prevent diseases, or identify and cure ailments in animals and lead to higher animal welfare ... in my opinion is not good to us ... (M2, FG4).

Other participants viewed genomic technologies as a way of improving productivity to meet the food security requirements of our ever-increasing global population, while to others, these technologies offered ways of protecting the environment and ensuring the existence of endangered species.

\subsubsection{Motivation by Financial Interests}

Participants expressed concerns about the motives of industry actors that drive the use of genomic technologies. Some participants believed that farmers and producers are motivated by profit alone. Others were concerned about the role of patent rights that have been generated from the use of genomic information and technology.

... It is just the huge businesses which will take over and then becomes another capitalist kind, you know where that transition occurs (F2, FG5).

... my fears of the money culture [referring to financial interests of corporations] ... (F, FG2).

\section{Discussion}

The research results indicated that, although additional information and clarification had been provided throughout the focus groups, there remained a general lack of participant differentiation between the different genomic technologies applied to farm animals. Participants expressed a preference for "non-invasive" technologies where no genetic modification or editing was applied, but where technological innovation was directed instead towards mapping existing animal genomes and used to selectively breed for desirable traits. Ethical concerns were frequently expressed about the technological processes being applied, particularly in relation to the extent to which such processes were perceived to be different from "natural" breeding techniques, and also in relation to the objective of the application, such as animal health and welfare or environmental protection, which tended to be viewed as more ethical than applications that increased yield or economic value within supply chains. However, exceptions to this increased ethical acceptability were those genomic applications that increased animals' tolerance of intensive production 
systems or lower welfare standards. This does not align with the argumentation proposed by Thompson [41], where it is proposed that genomic disenhancement, which changes the telos of animals so as to enhance animal welfare in intensive animal production systems, is acceptable. The results appear to reflect Thompson's perspective that there are moral intuitions that militate against animal enhancement in the absence of strong philosophical arguments against it. Some ethicists argue that disenhancement may be a temporary measure to relieve animal suffering in environments that humans have created for them [42], although it has, in turn, been argued that it is better to address the conditions that give rise to poor welfare [43] (an issue also raised in the focus group discussions), or indeed rethink the concept of telos to address what "is important" to an animal [44]. Further research to understand differences between the ethical reasoning of experts and public representations of and beliefs about the same issues is required.

When provided with further information about the different technological innovations applied to animals, participants expressed the view that gene editing (where the cell's genome can be cut at a desired location, allowing existing genes to be removed and/or new ones added, representing the precise and targeted alteration of a DNA sequence in a living cell) was preferred over and above genetic modification (involving the transfer of genetic material from another species) and the use of gene drives (which propagates a particular suite of genes throughout a population by altering the probability that a specific allele will be transmitted to offspring). The latter were associated with perceptions of unnaturalness and uncontrollability, as well as being perceived to increase risks to human and animal health, as well as the environment. The observation was that the focus group participants were more accepting of genomic technologies (for example, accelerated breeding) that did not result in "invasive" genetic changes but allowed a more rapid and precise strategy to genetic change based on the "observation" of genes rather than the introduction of artificial genetic changes. This suggests that it is not the concept of genetic change that is of concern to the public, but rather the technological mechanism by which it is achieved, and the extent to which this can be obtained using natural breeding techniques. As has been found in previous research studies, the perceived potential for unintended health and environmental impacts associated with genetic technologies (e.g., see $[43,44])$, and ineffective or contradictory regulatory mechanisms to control and mitigate these (e.g., see $[45,46])$, contributed to these concerns.

Participants recognised the transboundary nature of potential risks and ethical issues and suggested that, as well as the need to include and address ethical issues in the construction of regulations associated with genomic technologies applied to animals and their products, there was also a need to include these in transboundary regulatory systems, given that the risks and ethical issues also had transboundary implications. Ethical concern was expressed about the continued use of genomic technologies to further the development of existing intensive animal production systems in their current trajectory (for example, through applying these technologies to disenhance negative animal behavioural responses to such production systems), rather than mitigating the problems by reassessing production system structures and regulation, and so improving animal health and welfare through changing current practices. Notably, many participants perceived that the application of some or all genomic technologies applied to animal production systems was, in fact, unregulated at a global scale. This could be associated with the lack of trust that consumers have in research institutions, governance practices, and industry [5,45]. Financial gain was perceived by many participants to motivate the biotechnology industry to use all genomic technologies in ways that are potentially detrimental to animal health and welfare (see also [46-50]). It was suggested that developing and communicating how governance systems work at local, regional, and international levels might reassure the public that good governance practices are being applied. Increased co-production involving all sectors of society, in the development of regulations, policies, and how these are applied and monitored, may increase societal trust in governance practices. However, it is important to note that many different perceptions and opinions are likely to be associated with differ- 
ent individuals and groups within the public, and understanding these differences is an important issue in relation to the co-production of policies.

The technologies considered in this research were all identified as having at least the potential of being used for breeding farm animals [51]. Those technologies, which were all viewed as a means of studying and accumulating knowledge about the genomes of organisms, were, however, viewed more favourably than those that were associated with structural changes to an animal's DNA. Participants did not really differentiate between different types of genomic technology unless prompted to do so, including in relation to their ethical concerns. There was general acceptance of traditional selective breeding techniques, and from this accelerated breeding technologies were also considered acceptable, assuming established breeding techniques were still used. However, those technologies where some modification of animal genetic structures was involved were considered less acceptable, although this was more pronounced for genetic modification than for gene editing such as the CRISPR-Cas9 technology. This suggests that a different labelling approach may be required for genetically modified, as distinct from gene-edited, animal products, as the latter may be more acceptable to concerned consumers than the former, although such an approach is not accommodated within some legal frameworks. For example, CRISPR-Cas9 technology is currently regulated under the GMO regulations in Europe [52]. The proponents of modern gene editing techniques such as CRISPR-Cas9 argue that such techniques can be used to give additional or more complex types of genetic changes to those that would occur naturally. This should therefore be taken into account in legislative frameworks, for example, in the EU definition [53]. The main question that needs to be addressed is whether products developed using gene editing should be regulated on the basis of the process or the final products' characteristics, or whether a hybrid approach should be taken (https:/ /www.europarl.europa.eu/RegData/etudes/ATAG/2020/641 535/EPRS_ATA(2020)641535_EN.pdf, accessed 10 March 2021). It is important that the technologies used to produce foods will be labelled on products in order to promote transparency in food systems and the availability of information for those who would like it.

Finally, the convergence on views of discussants about the use of genomic technologies and information to facilitate human health care and veterinary research could be linked to the increasing role of genomics in health care $[52,53]$. While noting the relative importance of genomic technologies in health care for both humans and animals, participants also suggested that there were potential unintended consequences of undesirable traits being passed to offspring as a consequence of genetic alteration.

\section{Conclusions}

This research suggests that the public are more positive about the use of (various) genomic technologies to study and accumulate genetic information about animals, including farm animals, and which inform and accelerate traditional breeding practices, compared to techniques that modify the genome of animals. There was more consensus regarding applications that improved information for conservation, environmental sustainability, health, and animal welfare, with the exception of animal "disenhancement". Maintaining the "telos" of animals was important to study participants. The integration of societal preferences into regulations and labelling strategies may increase public trust in science and regulatory institutions, but further research in different cultural contexts and at scale is needed to enable a "co-produced" future regulatory landscape to be developed.

Author Contributions: Conceptualization, L.J.F., E.G. and D.C; methodology, L.J.F.; formal analysis, F.Z.N., D.C.; investigation, D.C., F.Z.N.; resources, E.G.; data curation, L.J.F.; writing-original draft preparation, F.Z.N., L.J.F., D.C., writing-review and editing, L.J.F.; supervision, L.J.F.; project administration, L.J.F., E.G.; funding acquisition, E.G., L.J.F. All authors have read and agreed to the published version of the manuscript. 
Funding: The authors would like to acknowledge Genome Canada and Genome Alberta who funded the research. The research was undertaken as part of a Genome Canada LSARP 2015 project "Application of genomics to improve disease resilience and sustainability in pork production" which is registered at the University of Alberta under the number RES0030284 and a Genome Canada LSARP 2015 project "“Increasing feed efficiency and reducing methane emissions through genomics: a new promising goal for the Canadian dairy industry", which is registered at the University of Alberta under the number RES0030198.

Institutional Review Board Statement: The study was conducted according to the guidelines of the Declaration of Helsinki The University Ethics Committee (UEC) is the formal body responsible for developing and implementing ethical policy and procedure. This research was approved by Newcastle University Ethics Committee, approval number 7235/2018).

Informed Consent Statement: Informed consent was obtained from all subjects involved in the study.

Data Availability Statement: Data are available from the corresponding author on request.

Conflicts of Interest: The authors have no conflict of interest.

\section{Appendix A. Scenarios Presented to Participants Regarding "Ethical Dilemmas"a}

- Scenario 1 was structured around the practice of tail removal in intensive pig production systems to prevent tail biting. Possible solutions to reducing pig tail biting were identified, which included (1) surgically removing the tails of pigs, (2) using genomic technologies to breed pigs without tails, (3) using genomic technologies to breed pigs that do not bite the tails of other pigs, and (4) reducing the intensity of the production system, so fewer pigs are in close proximity and with larger housing, which would reduce the incidence of tail biting.

- Scenario 2 was structured around the practice of debeaking chickens within intensive production systems to prevent inter-bird aggression. Potential solutions included (1) breeding chickens without beaks that could not, therefore, engage in these behaviours, (2) breeding chickens that are blind and so are not concerned about the proximity of other chickens, which would prevent problems associated with aggressive behaviours, and (3) putting fewer chickens in close proximity to each other and providing larger housing, which would have similar impacts on aggressive behaviours in chickens.

\section{References}

1. Nadathur, S.R.; Wanasundara, J.P.D.; Scanlin, L. Proteins in the diet: Challenges in feeding the global population. In Sustainable Protein Sources; Academic Press: Cambridge, MA, USA, 2017; pp. 1-19.

2. Boland, M.J.; Rae, A.N.; Vereijken, J.M.; Meuwissen, M.P.; Fischer, A.R.; van Boekel, M.A.; Rutherfurd, S.M.; Gruppen, H.; Moughan, P.J.; Hendriks, W.H. The future supply of animal-derived protein for human consumption. Trends Food Sci. Technol. 2013, 29, 62-73. [CrossRef]

3. Clark, B.; Stewart, G.B.; Panzone, L.A.; Kyriazakis, I.; Frewer, L.J. A systematic review of public attitudes, perceptions and behaviours towards production diseases associated with farm animal welfare. J. Agric. Environ. Ethics 2016, 29, 455-478. [CrossRef]

4. $\quad$ Clark, B.; Panzone, L.A.; Stewart, G.B.; Kyriazakis, I.; Niemi, J.K.; Latvala, T.; Tranter, R.; Jones, P.; Frewer, L.J. Consumer attitudes towards production diseases in intensive production systems. PLoS ONE 2019, 14, e0210432. [CrossRef]

5. Frewer, L.J.; Kleter, G.A.; Brennan, M.; Coles, D.; Fischer, A.R.; Houdebine, L.M.; Mora, C.; Millar, K.; Salter, B. Genetically modified animals from life-science, socio-economic and ethical perspectives: Examining issues in an EU policy context. New Biotechnol. 2013, 30, 447-460. [CrossRef]

6. Proudfoot, C.; Burkard, C. Genome editing for disease resistance in livestock. Emerg. Top. Life Sci. 2017, 1, $209-219$.

7. Bruce, A. Genome edited animals: Learning from GM crops? Transgenic Res. 2017, 26, 385-398. [CrossRef]

8. Jin, S.; Clark, B.; Kuznesof, S.; Lin, X.; Frewer, L.J. Synthetic biology applied in the agrifood sector: Public perceptions, attitudes and implications for future studies. Trends Food Sci. Technol. 2019, 91, 454-466. [CrossRef]

9. Critchley, C.; Nicol, D.; Bruce, G.; Walshe, J.; Treleaven, T.; Tuch, B. Predicting public attitudes toward gene editing of germlines: The impact of moral and hereditary concern in human and animal applications. Front. Genet. 2019, 9, 704. [CrossRef] [PubMed]

10. Kato-Nitta, N.; Maeda, T.; Inagaki, Y.; Tachikawa, M. Expert and public perceptions of gene-edited crops: Attitude changes in relation to scientific knowledge. Palgrave Commun. 2019, 5, 1-14. [CrossRef] 
11. Yang, Y.; Hobbs, J.E. Supporters or opponents: Will cultural values shape consumer acceptance of gene editing? J. Food Prod. Mark. 2000, 26, 17-37. [CrossRef]

12. Basinskiene, L.; Seinauskiene, B. Gene Editing Versus Gene Modification: Awareness, Attitudes and Behavioral Intentions of Lithuanian Consumers, Producers, and Farmers. Chem. Eng. Trans. 2021, 87, 433-438.

13. Yunes, M.C.; Osório-Santos, Z.; von Keyserlingk, M.A.; Hötzel, M.J. Gene Editing for Improved Animal Welfare and Production Traits in Cattle: Will This Technology Be Embraced or Rejected by the Public? Sustainability 2021, 13, 4966. [CrossRef]

14. Busch, G.; Ryan, E.; von Keyserlingk, M.A.; Weary, D.M. Citizen views on genome editing: Effects of species and purpose. Agric. Hum. Values 2021, 38, 1-14. [CrossRef]

15. Frewer, L.J.; van der Lans, I.A.; Fischer, A.R.; Reinders, M.J.; Menozzi, D.; Zhang, X.; van den Berg, I.; Zimmermann, K. Public perceptions of agri-food applications of genetic modification-a systematic review and meta-analysis. Trends Food Sci. Technol. 2013, 30, 142-152. [CrossRef]

16. Rose, K.M.; Brossard, D.; Scheufele, D.A. Of society, nature, and health: How perceptions of specific risks and benefits of genetically engineered foods shape public rejection. Environ. Commun. 2020, 14, 1017-1031. [CrossRef]

17. Franklin, S. Dolly Mixtures: The Remaking of Genealogy; Duke University Press: Durham, NC, USA, 2007. [CrossRef]

18. Raue, M.; Lermer, E.; Streicher, B.; Slovic, P. Psychological Perspectives on Risk and Risk Analysis; Springer: Berlin/Heidelberg, Germany, 2018; pp. 2-18.

19. Slovic, P. Understanding perceived risk: 1978-2015. Environ. Sci. Policy Sustain. Dev. 2016, 58, 25-29. [CrossRef]

20. Hassan, A.E.; Afroz, N. Implications of Risk Governance in Genetically Modified Food: A Comparative Discussion on European and United States Contexts. Asian Soc. Sci. 2020, 16, 33-42. [CrossRef]

21. Tait-Burkard, C.; Doeschl-Wilson, A.; McGrew, M.J.; Archibald, A.L.; Sang, H.M.; Houston, R.D.; Whitelaw, C.B.; Watson, M. Livestock 2.0-genome editing for fitter, healthier, and more productive farmed animals. Genome Biol. 2018, 19, 1-11. [CrossRef] [PubMed]

22. Burkard, C.; Lillico, S.G.; Reid, E.; Jackson, B.; Mileham, A.J.; Ait-Ali, T. Precision engineering for PRRSV resistance in pigs: Macrophages from genome edited pigs lacking CD163 SRCR5 domain are fully resistant to both PRRSV genotypes while maintaining biological function. PLoS Pathog 2017, 13, 1-28. [CrossRef]

23. Menchaca, A.; Dos Santos-Neto, P.C.; Mulet, A.P.; Crispo, M. CRISPR in livestock: From editing to printing. Theriogenology 2020, 150, 247-254. [CrossRef]

24. Mueller, M.L.; Cole, J.B.; Sonstegard, T.S.; Van Eenennaam, A.L. Comparison of gene editing versus conventional breeding to introgress the POLLED allele into the US dairy cattle population. J. Dairy Sci. 2019, 102, 4215-4226. [CrossRef]

25. Ufer, D.; Ortega, D.L.; Wolf, C.A. Economic foundations for the use of biotechnology to improve farm animal welfare. Trends Food Sci. Technol. 2019, 91, 129-138. [CrossRef]

26. Clark, B.; Stewart, G.B.; Panzone, L.A.; Kyriazakis, I.; Frewer, L.J. Citizens, consumers and farm animal welfare: A meta-analysis of willingness-to-pay studies. Food Policy 2017, 68, 112-127. [CrossRef]

27. European Commission. Attitudes of Europeans towards Animal Welfare European Union: Director Generate for Health and Social. Special Eurobarometer. 2016. Available online: http://ec.europa.eu/COMMFrontOffice/publicopinion/index.cfm/ Survey/getSurveyDetail/instruments/SPECIAL/surveyKy/2096 (accessed on 29 March 2021).

28. Spooner, J.M.; Schuppli, C.A.; Fraser, D. Attitudes of Canadian citizens toward farm animal welfare: A qualitative study. Livestock Science 2014, 163, 150-158. [CrossRef]

29. Verbeke, W.; Pérez-Cueto, F.J.A.; Barcellos, M.D.; Krystallis, A.; Grunert, K.G. European citizen and consumer attitudes and preferences regarding beef and pork. Meat Sci. 2010, 84, 284-292. [CrossRef] [PubMed]

30. Quinlan, M.M.; Smith, J.; Layton, R.; Keese, P.; Agbagala, M.; Lorelie, U.; Palacpac, M.B.; Ball, L. Experiences in engaging the public on biotechnology advances and regulation. Front. Bioeng. Biotechnol. 2010, 4, 3. [CrossRef]

31. Costa-Font, M.; Gil, J.M.; Traill, W.B. Consumer acceptance, valuation of and attitudes towards genetically modified food: Review and implications for food policy. Food Policy 2008, 33, 99-111. [CrossRef]

32. Callaway, E. CRISPR plants now subject to tough GM laws in European Union. Nature 2018, 560, 16-17. [CrossRef]

33. Friedrichs, S.; Takasu, Y.; Kearns, P.; Dagallier, B.; Oshima, R.; Schofield, J.; Moreddu, C. Policy considerations regarding genome editing. Trends Biotechnol. 2019, 37, 1029-1032. [CrossRef]

34. Jones, M.S.; Delborne, J.A.; Elsensohn, J.; Mitchell, P.D.; Brown, Z.S. Does the US public support using gene drives in agriculture? And what do they want to know? Sci. Adv. 2019, 5, 8462. [CrossRef]

35. Calabrese, C.; Featherstone, J.D.; Robbins, M.; Barnett, G.A. Examining the relationship between gene editing knowledge, value predispositions, and general science attitudes among US farmers, scientists, policymakers, and the general public. J. Sci. Commun. 2021, 20, A02. [CrossRef]

36. Boersma, R.; Poortvliet, P.M.; Gremmen, B. The elephant in the room: How a technology's name affects its interpretation. Public Underst. Sci. 2019, 28, 218-233. [CrossRef] [PubMed]

37. Hennink, M.M. Focus Group Discussions; Oxford University Press: Oxford, UK, 2013.

38. Verhoog, H. Defining positive welfare and animal integrity. In Diversity of Livestock Systems and Definition of Animal Welfare; University of Reading: Reading, UK, 2000; pp. 108-119.

39. Noll, S. Balancing Food Security and Ecological Resilience in the Age of the Anthropocene. In Food, Environment, and Climate Change: Justice at the Intersections; Rowman \& Littlefield: Lanham, MD, USA, 2018; pp. 179-192. 
40. Terry, G.; Hayfield, N.; Clarke, V.; Braun, V. Thematic analysis. SAGE Handb. Qual. Res. Psychol. 2017, 2, 17-37.

41. Thompson, P.B. The opposite of Human Enhancement:Nanotechnology and the blind chicken problem. Nanoethics 2008, 2, 305-316. [CrossRef]

42. Fischer, B. In defense of neural disenhancement to promote animal welfare. In Neuroethics and Nonhuman Animals; Johnson, L., Fenton, A., Shriver, A., Eds.; Springer: Cham, Switzerland, 2020; pp. 135-150.

43. Wawrzyniak, D. Why fitting animals itself is ethically dubious. Landbauforsch.-J. Sustain. Org. Agric. Syst. 2020, 70, 1-4.

44. Kramer, K.; Meijboom, F.L.B. Using Breeding Technologies to Improve Farm Animal Welfare: What is the Ethical Relevance of Telos? J. Agric. Environ. Ethics 2021, 34, 1-18. [CrossRef]

45. Vidal, N.; Barbosa, H.; Jacob, S.; Arruda, M. Comparative study of transgenic and non-transgenic maize (Zea mays) flours commercialized in Brazil, focussing on proteomic analyses. Food Chem. 2015, 180, 288-294. [CrossRef]

46. Frewer, L.J.; Bergmann, K.; Brennan, M.; Rene, L.; Meertens, R.; Rowe, G.; Siegrist, M.; Vereijken, C.M.J.L. Consumer response to novel agri-food technologies: Implications for predicting consumer acceptance of emerging food technologies. Trends Food Sci. Technol. 2011, 22, 442-456. [CrossRef]

47. Pidgeon, W.; Pidgeon, N.F. Trust in risk regulation: Cause or consequence of the acceptability of GM food? Risk Anal. Int. J. 2005, 25, 199-209. [CrossRef] [PubMed]

48. Fleming, A.; Abdalla, E.A.; Maltecca, C.; Baes, C.F. Invited review: Reproductive and genomic technologies to optimise breeding strategies for genetic progress in dairy cattle. Arch. Fuer Tierz. 2018, 61, 43. [CrossRef]

49. Onyango, B.; Ferdaus, H.; Hallman, W.; Schilling, B.; Adelajan, A. Public Perceptions of Food Biotechnology: Uncovering Factors Driving Consumer Acceptance of Genetically Modified Food. J. Food Distrib. Res. 2003, 34, 37-42.

50. Savadori, L.; Savio, S.; Nocotra, E.; Rumiati, R.; Finucane, M.; Slovic, P. Expert and public perception of risk from biotechnology. Risk Anal. 2004, 24, 1289-1299. [CrossRef] [PubMed]

51. Coles, D.; Frewer, L.J.; Goddard, E. Ethical issues and potential stakeholder priorities associated with the application of genomic technologies applied to animal production systems. J. Agric. Environ. Ethics 2015, 28, 231-253. [CrossRef]

52. European Court of Justice. Judgement of the Court (Grand Chamber), 25 July 2018 in Case C-528/16. 2018. Available online: http: / / curia.europa.eu/juris / document/ document.jsf?text=\&docid=204387\&pageIndex=0\&doclang=en\&mode=req\&dir= \&occ=first\&part=1\&cid=133112 (accessed on 29 March 2021).

53. van der Meer, P.; Angenon, G.; Bergmans, H.; Buhk, H.J.; Callebaut, S.; Chamon, M.; Eriksson, D.; Gheysen, G.; Harwood, W.; Hundleby, P.; et al. The status under EU law of organisms developed through novel genomic techniques. Eur. J. Risk Regul. 2020, 1-20. [CrossRef] 